AC 2011-1277: DEVELOPMENT OF A HIGH SCHOOL ENGINEERING RESEARCH PROGRAM: FINDINGS FROM A RESEARCH EXPERIENCE FOR TEACHERS (RET) SITE

Amy E. Landis, University of Pittsburgh

Dr. Christian D Schunn, University of Pittsburgh

Monica Christine Rothermel, University of Pittsburgh

Scott Shrake, University of Pittsburgh

Briana Niblick, University of Pittsburgh

Briana Niblick is a PhD student and NSF IGERT Fellow in the Sustainability and Green Design research group. 


\title{
Development of a High School Engineering Research Program: Findings from a Research Experience for Teachers (RET) Site.
}

\begin{abstract}
Students' first exposure to engineering all too often occurs at the university level. Engineering is rarely taught in high school, although as professors and teachers begin to recognize this delay in instruction, high schools are beginning to introduce engineering concepts into their curricula.

One program that promotes high school engineering instruction through collaboration with local universities is the National Science Foundation's Research Experience for Teachers program (NSF RET). The University of Pittsburgh hosts one such site with the aim of bringing engineering design into urban high schools via real world applications. One element of the RET Site brings high school students into research laboratories at the University of Pittsburgh. This paper presents an introduction to the RET program and delves into the findings from the internship portion of the RET Site.
\end{abstract}

The RET Site at the University of Pittsburgh has four main components including curriculum development for Pittsburgh area high school teachers during an intensive summer experience, teacher implementation of new engineering design units into their courses, an annual design competition where the teachers' students present their projects, and finally high school student internships within research laboratories at the University of Pittsburgh. Interns participated in research activities with the aim of developing their interest in engineering, developing their ability to perform research, and developing their engineering skills. Throughout the internship, students were given the opportunity to work with graduate students and university professors on current research projects, and they were exposed to graduate-level research activities through their participation in book discussion groups, research seminars, a research methods course, and a laboratory safety course. The students' internship culminated with a final written report and presentation during a symposium.

High school student interns during the summers of 2009 and 2010 participated in two different types of internship experiences. The first experience focused on advancing the students' design that originated in their classroom experience. Students were given the opportunity to improve the designs that won them the internship from the RET design competition with guidance from graduate student mentors and professors. The second experience allowed students to advance their classroom design, but also included them in existing research activities at the University.

Student creativity, interest in engineering, knowledge of engineering fields, and skill development was assessed through focus groups, evaluation of student journaling, and student surveys. Students in the different types of experiences showed different levels of engagement in research and differing perceptions related to engineering. Students from the first experience that focused on advancing their classroom project showed more resistance to change and were slower to come to creative engineering solutions. From the findings of this study, we discuss best practices and recommendations for incorporating high school students into a university laboratory setting. 


\section{Introduction}

The National Science Foundation's Research Experience for Teachers (NSF RET) "supports the active involvement of K-12 science, technology, engineering, computer and information science, and mathematics (STEM) teachers and community college faculty in engineering and computer science research in order to bring knowledge of engineering, computer science, and technological innovation into their classrooms" (NSF solicitation 11-509).

The RET program at the University of Pittsburgh (Pitt) is designed to better equip K-12 educators with the knowledge, understanding, and tools needed to effectively teach STEM topics to their students. The overall goal of the program is to improve the early education of K-12 students in STEM fields in order to better prepare students to be successful in college STEM programs.

After teachers participate in a summer training program, they are able to bring their findings back to the classroom and have the opportunity to engage students in active learning through an annual design competition. From the design competition, promising high school students are selected to participate in a summer research internship at Pitt to further their education and awareness of STEM fields. While the teacher training portion of the program is common among all NSF RET sites, the high school student internship portion is unique.

Findings from the program suggest that, overall, the RET program is effective for preparing high school students for a STEM program in college, but conclusions from the high school internship portion are not as clear. Because the financial and time commitments necessary to hold this portion of the program are significant, conclusions and recommendations must be made to ensure this portion is successful and supports the overall goal of the RET program. Findings from the RET program at Pitt and an assessment of two of the high school internship periods are reported to improve Pitt's RET Site and to provide guidance to other RET sites interested in modifying or expanding their programs.

\section{Pitt's RET Site}

Established in the spring of 2005, the core objective of Pitt's RET Site is to develop strategies that address the critical challenges facing our K-12 educational system in STEM fields. These well-documented challenges ${ }^{1-2}$ relate to the degradation of our nation's technological competitiveness and the significant decline in the number of K-12 students interested in STEM subjects. Many have argued that educators of our next generation of technical leaders, particularly those at the pre-college level, are the critical links for overcoming these challenges. Thus, our approach is to expose and train teachers on what it means to be an engineer through research and translational activities, and then leverage curricular approaches that allow them to directly transition this knowledge into high impact experiences for their K-12 students.

The Pitt RET Site places RET participants in state-of-the-art research projects and guides them through a design process that culminates in the realization of an actual product that is based on fundamental technology. Our teachers not only perform basic research, but they bring 
fundamental science to practice, which is the definition of engineering. The University of Pittsburgh is fortunate to have several interdisciplinary units that have forged together to make this connection possible - the Swanson School of Engineering's (SSOE's) Mascaro Center for Sustainable Innovation (MCSI), the SSOE's Swanson Center for Product Innovation (SCPI) and the Learning Research and Development Center (LRDC). Since the onset of our RET program, researchers from LRDC have worked closely with RET participants to help them translate handson design based learning activities into learning strategies that meet state standards and emphasize core science and technology concepts.

Quality of Life technology is the overarching theme for the Pitt RET site. Quality of Life technology is related to the development of products and processes that transform lives in a large and growing segment of the population-people with reduced functional capabilities due to aging or disability. Research projects range from the design of sustainable and potable water treatment technologies to the design of an anatomically correct hand.

The RET at Pitt includes four major components: 1) curriculum development for Pittsburgh area high school teachers during an intensive summer experience, 2) teacher implementation of new engineering design units into their courses, 3) an annual design competition where the teachers' students present their projects, and 4) high school student internships in university research labs.

A snapshot of the Pitt RET program's longitudinal timeline is shown in Figure 1. The process begins in February, when we start recruiting 8-9 new teachers into the program. To serve as mentors during the summer, we typically invite at 1-2 teachers back from the previous summer to make the total number of RET participants ten. These teacher mentors are selected based on demonstrated leadership skills and a strong understanding of the RET program objectives. Once the teachers have been recruited and have attended an orientation meeting, the teachers begin an intensive 8-week summer experience. The 8-week session begins with a kick-off day where the teachers are assigned teams and research projects, meet their mentors and research groups, and are given tours and assigned space in their research labs. As discussed later in this Section, the teachers participate in highly structured, team oriented research projects and curricular development activities during the summer program. During the first semester of the academic year, the teachers implement the in-depth 6-8 week design based learning (DBL) curricular modules that they developed during the summer. The end of the curricular modules includes a local class-wide team design competition whose winners are invited to a citywide design competition for all of the winning students of the teachers that have participated in our RET program. The citywide competition annually brings together over 150 participants each year and is held in January or February. Students from the top team in this competition are then invited to participate in a five-week engineering laboratory internship where they have continued developing their designed products.

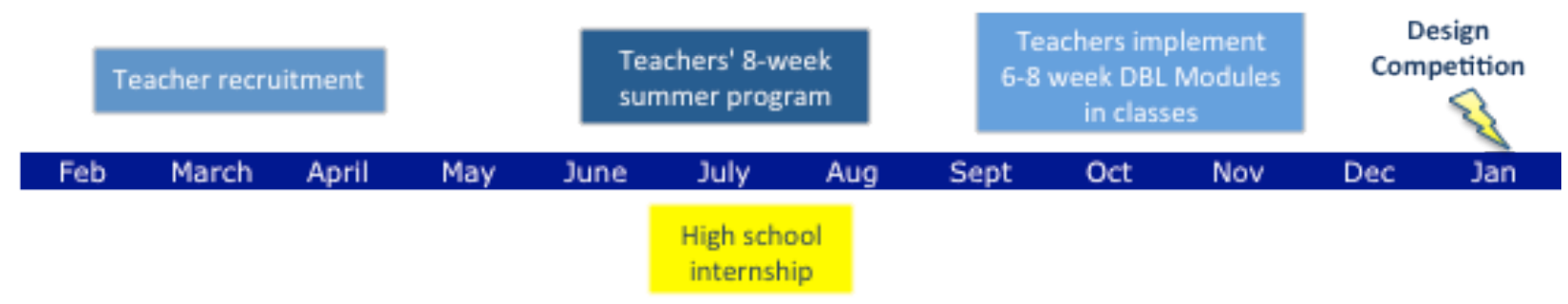




\section{Figure 1. Pitt RET Timeline}

During the summer, the RET teachers are required to work on design-based learning (DBL) units for their high school science classrooms. DBL is a form of project-based learning in which students learn what they need to learn in a just-in-time fashion while trying to design something ${ }^{3-4}$. The goal of these DBL units is to: a) inspire a broad cross-section of high school students to want to become engineers and $b$ ) to transform their science classrooms so that they will graduate high school with a foundation of knowledge such that they will do well as undergraduate engineers. This work is done in the context of current high school science classrooms that suffer from many problems: 1) state standards typically require many different topics to be reviewed in a time-frame that is unrealistic; 2) students may not appreciate why the material is relevant to everyday life or their future careers; 3) many teachers do not fully understand the content they are teaching; and 4) many teachers have weak inquiry-based pedagogical skills ${ }^{5}$.

To change this situation, we must have teachers do more than create a few lectures or demos based on their summer research experiences and we must provide a large amount of support for teachers to help them create powerful learning experiences in their classrooms. Our curricular approach is 6-to-8-week-long DBL experiences that can be implemented at the beginning of high school. Pitt's LRDC has created a general template for such a curriculum unit that can be applied across physics, chemistry, biology, and earth sciences.

Findings from the RET Site

Our past efforts demonstrate the value of training K-12 teachers to grasp fundamental engineering concepts as illustrated in the SSOE Pitt Engineering Career Access Program (PECAP). The mission of PECAP is to promote diversity within engineering and lead underrepresented students into our student body. In this program, underrepresented pre 10th-12th grade Pittsburgh Public (PPS) high school students spend their summer in the SSOE taking math and science courses and participating in hands-on engineering activities.

As shown in Table 1, the PECAP program has been highly successful with respect to nearly $100 \%$ participant enrollment in four-year colleges. The impact of this program on students entering engineering, however, was drastically different; from 2001-2004 only 10\% of students enrolled in engineering fields. These outcomes were especially puzzling given the strong interest expressed by $88 \%$ of students to pursue a major in engineering during their exit interviews. Searching for an answer to this trend, Schunn et al. discovered that while $88 \%$ of K-12 teachers believe that engineering is important for understanding the world around us, only $30 \%$ of teachers feel that their students could succeed as engineers ${ }^{6}$. As the college-bound PECAP students went back to school, it is likely that their high school teachers did not steer them toward engineering majors because many of them did not understand what it meant to be an engineer and may have felt that engineering was too hard for their students. Since starting our RET site with PPS in 2005, we have had a significant impact with $25 \%$ of students entering engineering following participation in the PECAP program. We largely attribute this improvement to our teachers' ability to use their engineering knowledge and implementing design-based engineering curricula to reinforce what the students learn during the summer ${ }^{7}$. 
Table 1. Students participating in Pitt's PECAP (2001-2004) and PECAP plus RET (20052006). Adapted from Lovell et al ${ }^{7}$.

\begin{tabular}{|l|c|c|c|c|c|c|}
\hline & $\mathbf{2 0 0 1}$ & $\mathbf{2 0 0 2}$ & $\mathbf{2 0 0 3}$ & $\mathbf{2 0 0 4}$ & $\mathbf{2 0 0 5}$ & $\mathbf{2 0 0 6}$ \\
\hline \# Graduates & 44 & 37 & 27 & 41 & 52 & 49 \\
\hline \# Enrolled in College & 44 & 36 & 27 & 40 & 52 & 49 \\
\hline \# Entered STEM Majors & 18 & 17 & 12 & 23 & 33 & 22 \\
\hline \# Entered Engineering Majors & 3 & 3 & 4 & 5 & 11 & 14 \\
\hline \# Pitt Engineers & 2 & 2 & 2 & 2 & 6 & 4 \\
\hline
\end{tabular}

\section{Assessment of High School Engineering Research Internships}

After high school students complete in-class design projects with the assistance of the RET teachers, they compete in a program-wide design competition. The winning student team is awarded a summer research internship at the University. The internship is held during a five week period in which students are assisted by university professors and graduate students to gain a better understanding of basic engineering principles.

The high school internship period of the RET program has varied over the years. After the 2010 summer internship, assessments were made concerning the design of the program and the impact this portion of the RET program had on participating students. The assessments were based on two groups of students consisting of 3 students in 2009 and 4 students in 2010. During the internship period in the summer of 2009, high school students were solely tasked with improving their winning high school project design. These students were given the opportunity to improve their winning design with guidance from graduate student mentors and professors in a university setting. In 2010, the group continued to improve their original design while also being immerged in university research activities.

\section{Assessment Methods}

Students' creativity, engineering interest, knowledge of engineering fields, and skill development were assessed qualitatively during the internship program. Assessments were based on the students' involvement in focus groups, the students' daily journaling, and observations made by mentors. Additionally, students were asked to write a one-page description of their expectations for the summer at the beginning of each internship period. Students revisited their expectations and commented on their accomplishments in final reports and presentations given to Pitt's RET program coordinators. Student writings and journals were not coded, but were collected and read regularly throughout the program.

At the close of each internship period, students participated in a focus group with their faculty advisor; they discussed what activities they were the most excited about, what activities they felt had the most benefit to their redesign, and their thoughts on college and engineering after high school. Field notes and logs kept by the faculty and graduate mentors at focus group meetings and throughout the internship were used in the assessment of the program. Following the 2010 internship, faculty and graduate mentors from the 2009 and 2010 internships met to discuss significant observations and findings. Field notes were taken at this group meeting, and logs kept by faculty and graduate mentors and were used as the basis of the assessment. 
The assessment of the high school internship programs was based on only two of the internship periods and was made following the completion of the programs, thus it is only intended to assist future program coordinators at Pitt and other RET sites in developing a curriculum for the high school student internships. The assessment is significant because of the unique student internship portion of the RET program at Pitt. Findings may not be universal, but they may assist educators in designing internships which give students the best opportunity for growth and preparation for undergraduate programs in STEM fields.

\section{Comparison of 2009 and 2010 Internships.}

The goals of the internship were the same for the 2009 and 2010 programs (as in other years of the program). Through the program, students were able to explore their interest in engineering, develop engineering skills, develop general research skills, and improve the design of an existing product. These goals were developed by students and their mentors at the beginning of the internship, and they were further discussed by students in a short paper written at the beginning of the internship. Throughout the internship, the students' progress was monitored through informal discussions and daily journal entries.

During the internships, the students were continuously exposed to university-level research activities. In 2010, they participated in mini-courses to learn about research methods and laboratory safety and attended a weekly reading group, where they had the opportunity to learn more about contemporary issues of the environment and sustainability. They also attended graduate research seminars where they gained deeper insight into a particular graduate student's research topic. The 2009 group only attended a laboratory safety class at the beginning of the summer and biweekly seminars covering research at Pitt. The RET interns from both years participated in the SSOE's undergraduate research program and had the opportunity to present their research in the Undergraduate Research Symposium. In addition to this oral presentation, the interns also wrote a report on their design and another report about their internship experiences.

\section{Internship Project Summary.}

The high school interns who participated in the 2009 internship designed a portable water treatment device that consisted of three 12" long and 3" diameter PVC pipe sections. Each pipe contained a separate step necessary for water filtration and treatment. The sections were able to be joined together to form the treatment method. The first step involved adding chlorine drops to the water, followed by running the water through the three combined sections for the filtration process which took about 45 minutes to bring water to potable standards.

The focus of the 2009 internship was for the students to advance the design that they had developed in the classroom and presented at the design competition. The initial design successfully brought water to potable standards; however the student seemed to be unaware that the overall length, bulk, and filtration time for the water treatment system were major hindrances in its ability to be an efficient and portable final product. The goal of the initial phase of the internship was to allow the students themselves to determine the aspects of their project that 
could best be improved. To this aim, the interns discussed their product and its associated strengths and weaknesses with their mentors. The initial redesign had mixed results as the students either had difficulty admitting that their product had weaknesses, or they believed the product was as well designed as possible.

Next, in order to enable the students identify ways to improve their product, they were taught the basics of a literature review and product research utilizing the Internet. The focus of their Internet research was to answer the following questions: "What determines a good water filter? How do we test/ measure the filter? What have other people done?" The results were that the students determined a filter had to make water potable, be made of ideal materials, and be portable. They then selected metrics to determine if the water was potable, how to decide ideal materials, and how to determine acceptable portability. Students seemed especially struck by information that they found on Wikipedia and then the 'How Stuff Works' website calling PVC the 'poison plastic.'

Finally, in order to encourage and inspire the students to further reevaluate their design; they went to a local REI store to explore existing products that offered portable water filtration and purification. The students seemed to grasp that there were a number of other methods to accomplish similar goals, but still had difficulty deviating from their original design. After their experiences at REI and the first few weeks of the internship, they developed a decision matrix to determine which portions of their product they would change. They were strongly committed to their initial design, and rather than a complete product overhaul they decided to make small changes to the product. Through the use of a decision matrix they determined that they would change the material from PVC to ABS. They also decided to shorten the length of their initial design as well as filtration time by about $5 \%$.

(a)

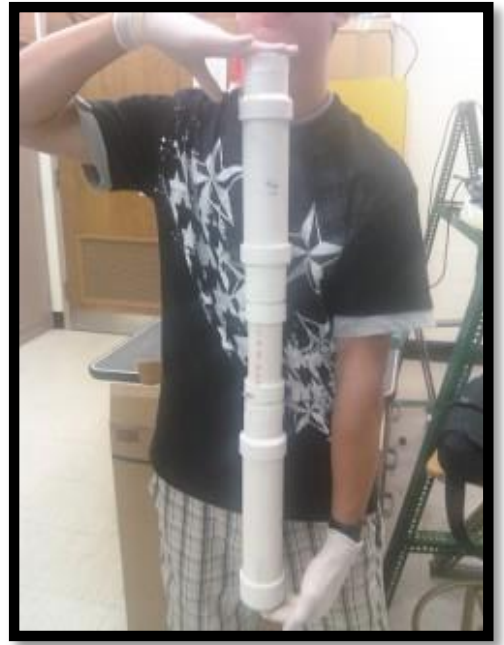

(b)

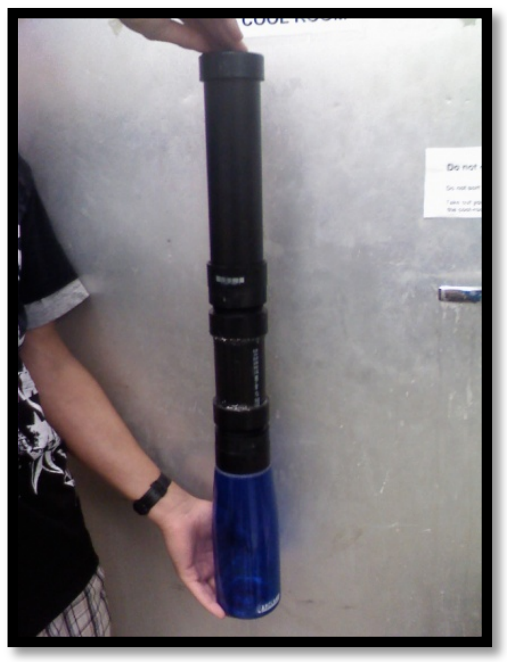

Figure 2. (a) Initial water filter design from 2009 internship, (b) Final water filter design from 2009 internship.

The students did successfully change and improve their final product; however they were very hesitant to make any major changes. Regardless of the direction provided or alternatives presented the students were firmly committed to their initial design. They seemed to grasp that 
the initial design could be improved; however they were resistant to making any major modifications. They also grasped the concepts of life cycle thinking and changed to a non PVC plastic, but failed to determine if the plastic they chose instead was actually better in any way. The students successfully grasped many of the engineering concepts they encountered throughout the internship, as was shown in their final presentation and design.

\section{Internship Project Summary.}

In 2010, the internship portion of the RET site was based on the winning design from the high school competition as in 2009, but the students were also involved with other aspects of university research. Students were exposed to elements of traditional engineering design as well newly emerging engineering fields. The students had originally designed a portable water filtration device. The original device was effective at removing pollutants from water, but it was also heavy and bulky. These students were also exposed to sustainability and green design through their participation in book clubs and other formal and informal discussions. Additionally, students were involved with an ongoing research project and assisted in data collection for a waste audit.

Similar to the students in 2009 , the students generally demonstrated an unwillingness to change views of their original project design. Students were reluctant to admit flaws in the original design and therefore did not see any reason to improve the design. Even after similar activities (such as the REI field trip) that allowed students to compare their product to similar water filtration devices already on the market, students had a tendency to put features of these products in a negative light if they did not compare to the students' project. Additionally, students from the 2010 group during one of their focus groups reported that little was gained from looking at other water filtration devices that had seen success in the market.

The end result of the 2010 student redesign was similar to the 2009 group; small aspects of the design such as materials used were changed, but the general design remained the same. The interns did not seriously consider a significant redesign until their original project failed because it was too heavy and collapsed. Although frustrating at the time, this event allowed the students to see that their idea could be improved and made better. The final design incorporated improved features such as making the product lighter and more portable, while most of the original features were kept intact.

(a)

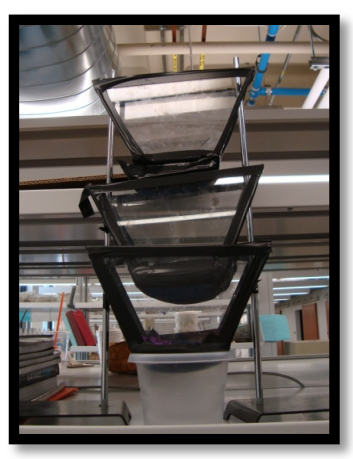

(b)

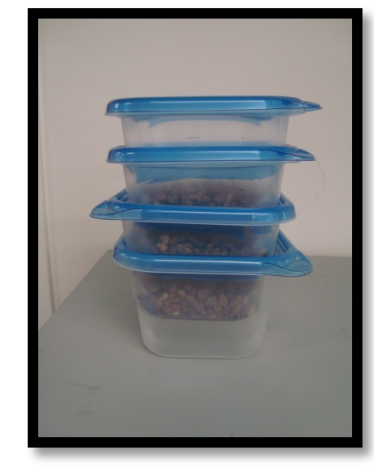

Figure 3. (a) Initial water filter design from 2010 internship, (b) Final water filter design from 2010 internship. 


\section{Findings from High School Student Internship}

Students were more open to new concepts when involved in existing university research projects. One project the 2010 students were heavily involved with was the waste audit, which consisted of a study on the end of life of compostable serviceware. Students were given the opportunity to learn and discuss the significance of the project as well in assisting in the collection of data for the project. At the beginning of the project, students had very little background in the subject area and were eager to learn about the subject and the results of the study.

In general, students showed a positive response to hands-on activities. They were more interested in the design, construction, and testing of their project than other aspects such as conducting a literature review and researching design concepts for their product. A similar response was shown for the other portions of the internship. For example, the students were more excited about conducting the waste audit than from the group discussions about waste management and reduction activities. Students claimed to benefit least from computer and Internet research. The students felt that this aspect of the design process was tedious, and it often took them much longer than expected to complete tasks. As a result, these assignments did not keep their interest.

The students also seemed to benefit more from smaller group activities than large group activities. Students were more open and willing to ask questions in smaller, informal group discussions than in large groups, such as the book club, when many graduate students and faculty were present. In these large groups, students commented that they were intimidated by the graduate students and felt that they lacked the knowledge to participate in discussions. Students were more open to discussion and developing their ideas in an atmosphere with only one or two graduate students or professors.

\section{Conclusions and Recommendations for the High School Student Internship}

The main focus of the internship and partnership with local high schools is to determine how to best teach engineering concepts while encouraging creativity and innovation to students for the first time. The major drawback of the past experiences has been that student interns were assigned to improve a design that had already won a major competition. Because a prize had already been won for their work, students were hesitant and sometimes strongly opposed to changing any part of the design that was too different from the original work.

In the future, more emphasis should be placed on introducing basic engineering principles to the high school students in the first portion of the internship. A basic principle to stress is that no design is perfect and that continual improvements are made in all engineering designs and processes. In order to teach better engineering principles, it may be beneficial to have all students work on and complete an existing university project in their field in order to best experience university research and engineering education.

Based on these findings, it is recommended that a qualitative study is developed and implemented to test the hypothesis that students benefit more from an internship focusing on aspects of engineering design differing from their initial design projects. A qualitative study 
may provide information necessary to apply these findings to a broader range of applications within the K-12 education community.

\section{Conclusions}

Findings from Pitt's RET Site show the success of the program as a whole at improving the teaching of STEM topics to K-12 students and increasing the participation of students in collegelevel STEM programs. The assessment of the high school student internship portion of the program revealed shortcomings in the program. Further program development is needed to ensure the completion of project goals through the internship program. Using this assessment of the program as a guideline, it is recommended that future high school student internships be altered to include University research activities in a familiar subject instead of only focusing on the redesign of the original design contest project. A qualitative, hypothesis driven case study may be used in the future to determine the effectiveness of this program.

Acknowledgements

Funding from the National Science Foundation (award \#0808675) supports the University of Pittsburgh's RET Site.

\section{Bibliography}

1. NSB. A National Action Plan for Addressing the Critical Needs of the U.S. Science, Technology, Education, and Mathematics Education System. In. Washington, D.C.: National Science Board; 2007.

2. Katehi L, Pearson G, Feder M. Engineering in K-12 education: Understanding the status and improving the prospects / Committee on K-12 Engineering. Washington, DC: National Academies Press; 2009.

3. Doppelt Y, Mehalik MM, Schunn CD, Silke E, Krysinski D. Engagement and achievements in design-based learning. Journal of Technology Education 2008;19(2):21-38. 4. Mehalik MM, Doppelt Y, Schunn CD. Middle-School Science Through Design-Based Learning versus Scripted Inquiry: Better Overall Science Concept Learning and Equity Gap Reduction. Journal of Engineering Education 2008;97(1):71-85.

5. Edelson D. Engineering pedagogical reform: A case study of technology supported inquiry. Paper presented at: NSF Inquiry Conference 2005.

6. Reynolds B, Mehalik MM, Lovell MR, Schunn CD. Increasing Student Awareness of and Interest in Engineering as a Career Option through Design-Based Learning. International Journal of Engineering Education 2009;25(4).

7. Lovell M, Reynolds B, Mehalik M, Schunn C. Lessons learned from a product realization RET site: maximizing success for teacher research and high school student impact. In: 2008 ASEE Annual Conference and Exposition. Pittsburgh, PA; 2008. 